\title{
$\mathrm{PVDF} / \mathrm{MgO}$ 마찰재를 이용한 마찰면진장치의 성능 분석
}

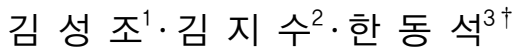

${ }^{1}$ 연세대학교 건설환경공학과 석사후연구원, ${ }^{2}$ 베를린 공과대학 토목공학과 박사후연구원, ${ }^{3}$ 연세대학교 건설환경공학과 교수

\section{Performance Analysis of Friction Pendulum System using PVDF/MgO Friction Material}

\author{
Sung-Jo Kim ${ }^{1}, \mathrm{Ji}-\mathrm{Su} \mathrm{Kim}^{2}$ and Tong-Seok $\mathrm{Han}^{3 \dagger}$ \\ ${ }^{1}$ Post-Master's Researcher, Department of Civil and Environmental Engineering, Yonsei University, Seoul, 03722, Korea \\ ${ }^{2}$ Postdoctoral Researcher, Department of Civil Engineering, Technische Universität Berlin, 13355, Germany \\ ${ }^{3}$ Professor, Department of Civil and Environmental Engineering, Yonsei University, Seoul, 03722, Korea
}

\begin{abstract}
Polytetrafluoroethylene (PTFE) is a commercialized friction material in friction pendulum systems used for earthquake hazard mitigation in structures, and it has excellent chemical resistance and frictional performance. However, PTFE has a relatively low wear resistance for the friction pendulum systems in service. As an alternative to PTFE, a cost-effective frictional material, polyvinylidene fluoride (PVDF) strengthened by magnesium oxide $(\mathrm{MgO})$, with enhanced wear resistance performance is proposed in this study. The frictional performance of the developed $\mathrm{PVDF} / \mathrm{MgO}$ was evaluated through experiments and compared with that of PTFE. Accordingly, a friction pendulum system was designed using the measured friction coefficient. The performance of this friction pendulum system was evaluated via nonlinear time history analyses of bridges. Subsequently, the plausibility of using PVDF/MgO as an alternative to PTFE as a friction material for friction pendulum systems was discussed.
\end{abstract}

Keywords : base isolation system, friction pendulum system, nonlinear time-history analysis, OpenSees

\section{1. 서 론}

미국과 중국, 일본 등 세계적으로 큰 규모의 지진이 발생하 여 많은 피해가 발생하였고, 우리나라에서도 최근 몇 차례 큰 규모의 지진이 발생함에 따라 내진설계를 주제로 하는 다양한 연구가 많은 관심을 받고 있다. 지진이 발생하면 지반운동에 의해 생성되는 에너지가 구조물에 전달되어 심각한 피해를 주 며, 유지보수를 위한 막대한 비용을 발생시킨다. 이러한 피해 를 감소시키기 위한 연구가 수행되고 있으며(Kim et al., 2020; Medhekar and Kennedy, 2000) 다양한 지진 피해 저감 방법들 이 교량, 건물 등 여러 구조물에 활용되고 있다. 여러 방법 중에 서 지진격리장치(seismic isolation device)도 구조물의 지진응 답 저감에 많이 활용되고 있다. 지진격리장치는 지진으로 인 해 발생하는 하중과 변위를 장치가 일정 구간 수용함으로써 구

\footnotetext{
${ }^{\dagger}$ Corresponding author:

Tel: +82-2-2123-5801; E-mail: tshan@yonsei.ac.kr

Received June 14 2021; Revised July 29 2021;

Accepted July 292021

(C) 2021 by Computational Structural Engineering Institute of Korea
}

조물에 전달되는 하중과 변위를 감소시키는 방법으로 구조물 에 발생하는 피해를 감소시킨다.

지진격리장치는 지진에너지를 소산하는 방법에 따라 세부 적으로 형식이 분류된다. 그 중에서 마찰재의 마찰력으로 감 쇠작용을 하며 마찰면의 곡률로 인해 발생하는 복원력으로 지 진에너지를 소산하는 마찰면진장치(friction pendulum system) 도 많이 사용되고 있다(Castaldo et al., 2015). 마찰면진장치는 규격이 정해져 상황에 따라 정해진 장치를 사용하는 것이 아 닌, 상부구조의 하중, 지진하중, 구조물의 목표주기 등을 고려 하여 상황에 맞게 새로 설계하여 사용하기 때문에 적용성이 높 아 교량, 건물, $\mathrm{LNG}$ 저장탱크 등에 널리 사용되고 있다.

마찰면진장치 내부에 위치한 마찰재의 재료는 현재 폴리테트 라플루오로에틸렌(polytetrafluoroethylene, PTFE)이 가장 많이 사용되고 있다. PTFE는 내화학성과 마찰성능이 우수하므로

This is an Open-Access article distributed under the terms of the Creative Commons Attribution Non-Commercial License(http://creativecommons. org/licenses/by-nc/3.0) which permits unrestricted non-commercial use, distribution, and reproduction in any medium, provided the original work is properly cited. 
마찰면진장치의 마찰재로 활용되고 있지만, 지진 발생 시 마 찰면진장치가 거동하면 마찰재에 마모가 크게 발생하므로 유 지보수가 까다롭다.

본 논문에서는 기존 마찰재(PTFE)의 마찰성능 수준을 가지 며 내마모성을 증가시킨 새로운 마찰재를 개발하여 마찰면진 장치의 내구성능을 개선하였다. 재료로는 두 가지를 활용하여 마찰재의 내마모성을 증가시킬 수 있었다. 마찰재는 직접 제 작하여 마찰계수 측정실험을 통해 마찰계수를 파악하고 교량 모델에 적용한 후 비선형 시간이력 해석을 통해 기존 마찰재가 적용된 면진장치와 같이 구조물의 내진성능을 증진시킬 수 있 다는 것을 확인하였다.

\section{2. 마찰재 개발}

\section{1 재료 선정}

마찰면진장치 성능 확보 및 개선을 위해 마찰면의 곡률과 마 찰재료에 관한 연구들이 수행되었다(Jangid, 2005; Lu et al., 2011). 특히 기존 마찰 재료인 PTFE를 대체할 수 있는 재료 개발에 대한 연구가 수행되고 있으며 고분자 복합체를 개선시키기 위해서 나노충전제(nanofiller)가 개발되었다(Burris and Sawyer, 2006; Takeichi et al., 2008). 본 논문에서는 다양한 마찰재료 중, PTFE 보다 값이 저렴하며 공정성이 뛰어나고 용해성이 높아 PTFE의 대체재로 평가받는 폴리비닐리덴 플루오라이드(polyvinylidene fluoride, PVDF)와(Liu et al., 2013), 나노충전제로 산화마그네 슘(oxide magnesium, $\mathrm{MgO}$ )을 이용하여 마찰재를 개발하였다.

$\mathrm{MgO}$ 는 $\mathrm{PVDF}$ 보다 가격이 저렴하므로 $\mathrm{MgO}$ 를 치환하여 사 용하는 경우 마찰재의 제작비용을 더 낮출 수 있다. 또한, PVDF 보다 내마모성이 우수하므로 마찰재의 마모율을 감소시킬 수 있다. Park 등(2019)의 연구에서 $\mathrm{MgO}$ 가 $10 \%, 20 \%, 30 \%$ 치환 된 것 중, $10 \%$ 치환된 경우 내마모성이 가장 높은 것으로 제시 하였다. 그러므로 $\mathrm{MgO}$ 가 $10 \%$ 치환된 $\mathrm{PVDF} / \mathrm{MgO}$ 마찰재를 제작하기 위해서 분말 형태인 PVDF(Fig. 1(a))와 $\mathrm{MgO}$ (Fig. $1(\mathrm{~b})$ )를 이용하였고, 제작방법은 2.2절에 나타내었다.

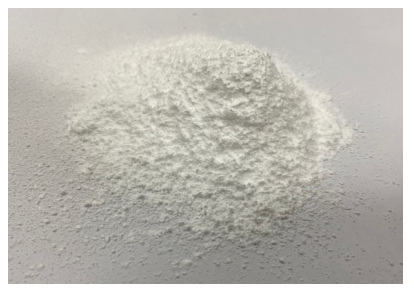

(a) PVDF

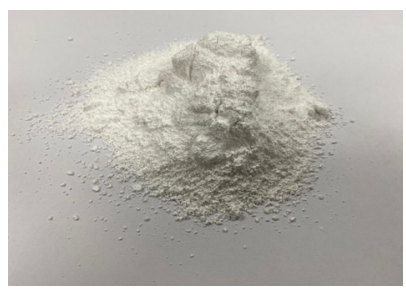

(b) $\mathrm{MgO}$
Fig. 1 Polyvinyledene fluoride(PVDF) and oxide magnesium(MgO) powders

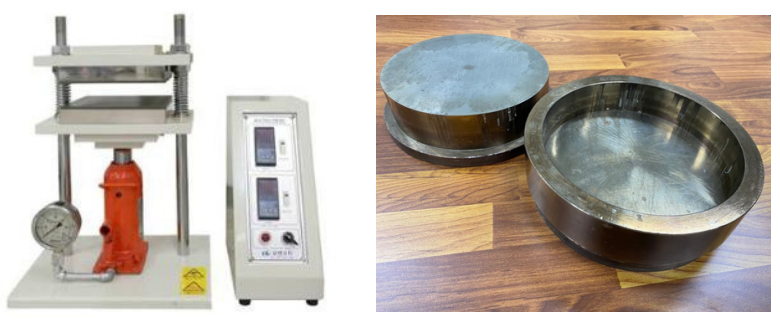

Fig. 2 Hot-press and mold to prepare sample in this study

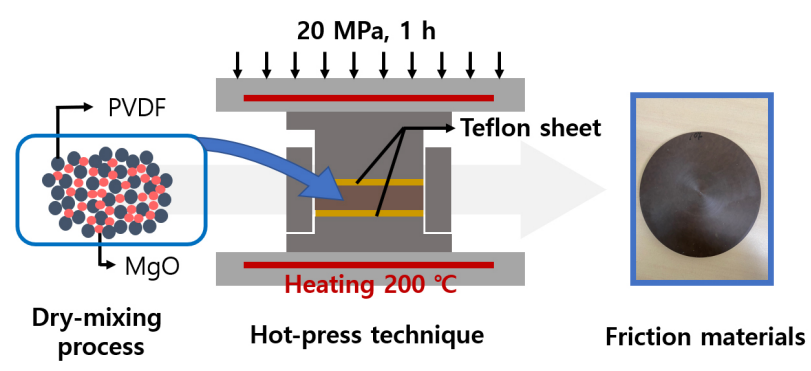

Fig. 3 Production process of PVDF/MgO friction material sample

\section{2 $\mathrm{PVDF} / \mathrm{MgO}$ 마찰재 제작}

$\mathrm{MgO}$ 가 $10 \%$ 치환된 $\mathrm{PVDF} / \mathrm{MgO}$ 마찰재 시편을 핫프레스 방식과 지름이 $170 \mathrm{~mm}$ 인 금형을 통해 제작하였다. 제작에 사 용된 핫프레스 기기와 금형은 Fig. 2와 같다.

핫프레스로 온도를 설정하고, 유압펌프로 압력을 유지할수 있 다. 몰드 안에 위치한 분말 상태인 $\mathrm{PVDF}$ 와 $\mathrm{MgO}$ 에 열과 압력이 전달되고, 융해된 후 냉각을 통해 응고되어 마찰재가 제작된다.

본 논문에서 사용되는 마찰재는 직경 $150 \mathrm{~mm}$ 와 두께 $3.5 \mathrm{~mm}$ 의 원판형태로 제작되었다. 마찰계수 실험 시 요구되는 최소 두께를 만족하기 위해 1 시간 동안 $200^{\circ} \mathrm{C}$ 의 온도와 $20 \mathrm{MPa}$ 의 압력을 가하였고, 시편이 급속히 축소되는 것을 방지하기 위 해 실온으로 냉각하였다. 제작과정은 도식화하여 Fig. 3 에 나 타내었다.

\section{3. $\mathrm{PVDF} / \mathrm{MgO}$ 마찰재 마찰계수 측정시험}

\section{1 시험조건 및 방법}

연구를 위하여 새롭게 제작한 마찰재의 마찰계수를 파악하기 위해 마찰계수 측정시험을 진행하였다. 시험에는 제작한 PVDF/ $\mathrm{MgO}$ 마찰재를 이용하였으며, 측정된 마찰계수는 AASHTO guide specification(AASHTO, 2010)에 제시된 PTFE 마찰재의 마찰 계수와 비교분석을 진행하였다.

마찰계수 측정시험은 면진장치 성능시험기(Fig. 4)를 이용 하여 진행되었다. 다양한 면압과 속도에 따른 마찰계수를 확 인하기 위하여 시험기의 실린더 속도는 $1 \mathrm{~mm} / \mathrm{sec}, 50 \mathrm{~mm} / \mathrm{sec}$ 를 
이용하였으며, 면압은 $10 \mathrm{MPa}, 20 \mathrm{MPa}, 30 \mathrm{MPa}$ 을 이용하여 시 험이 진행되었다. $\pm 50 \mathrm{~mm}$ 의 변위를 정해진 속도에 따라 4 번 왕복으로 거동하며 발생하는 수평하중을 응답으로 나타내고, 이 응답을 이용해 AASHTO 가이드라인에서 제시한 방법으 로 마찰계수를 계산하였다. 계산 방법은 시험을 통해 얻은 하 중-변위 응답에서 마지막 응답을 제외한 나머지 하중 사이클 응답을 평균하고, 평균한 응답과 $\mathrm{y}$ 축 양의 지점에서 만나는 값인 특성 강도(characteristic strength)를 면진장치 성능시험 기로 마찰재에 작용시킨 수직 하중과의 비율로 마찰계수를 계산한다. 마지막 사이클 응답은 면진장치 성능시험기가 시 험이 종료된 후 원점으로 돌아오지 않아 하중-변위 응답이 폐 합 되지 않을 수 있으므로 특성 강도 값에 영향을 미칠 수 있기 때문에 제외한다. 마찰계수 측정 방법은 도식화하여 Fig. 5 에 나타내었다.

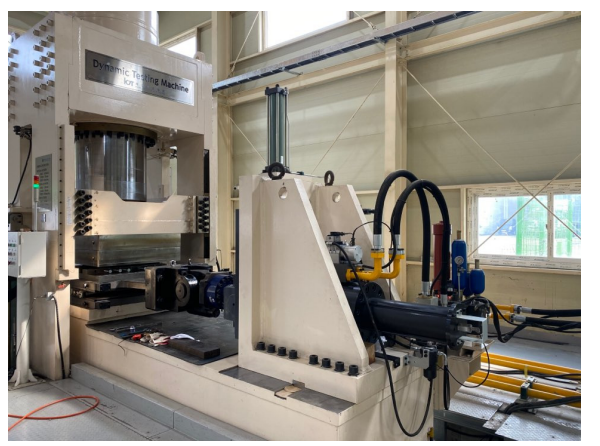

Fig. 4 Dynamic test machine for base isolation systems

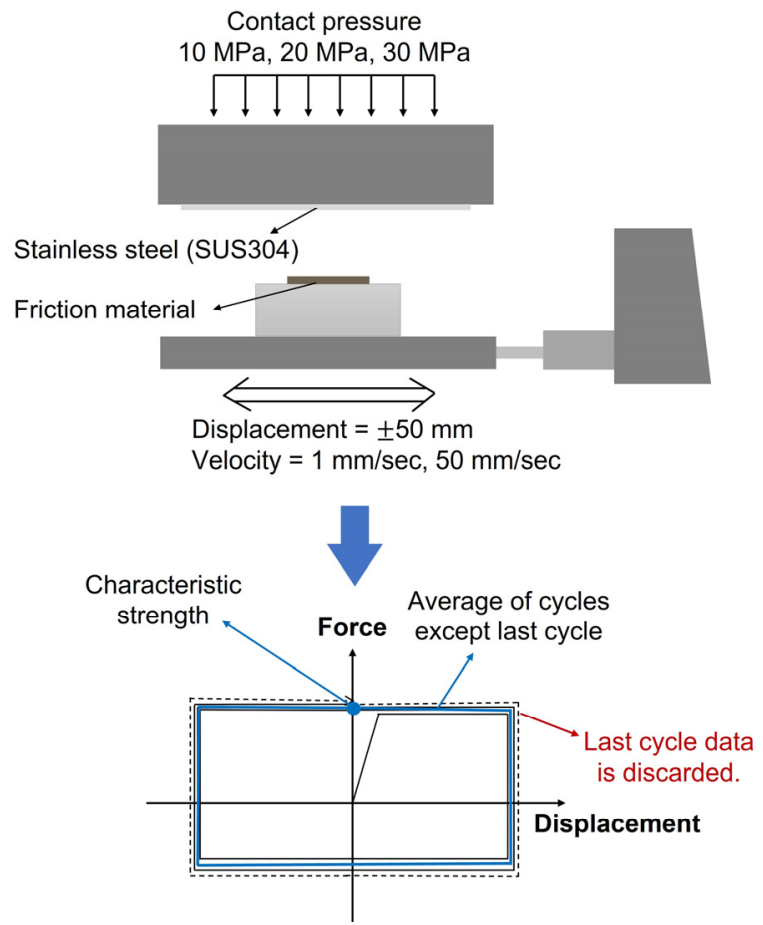

Fig. 5 Process of friction coefficient measurement

\section{2 마찰계수 측정시험 결과 및 분석}

면진장치 성능시험기를 통해 Fig. 6과 같은 하중-변위 응답 을 얻을 수 있으며, 이를 이용하여 3.1절에서 설명한 방법으로 속도와 면압에 따른 마찰계수를 각각 계산하였다. 계산된 마 찰계수는 Table 1 에 제시하였다.

AASHTO 가이드라인에 따르면 일반 PTFE 마찰재의 경우 마찰계수가 면압에 따라 다르게 제시되어 있다. 마찰재에 작 용하는 면압이 비교적 낮은 수치인 $3.45 \mathrm{MPa}$ 이 작용할 때 마찰 계수는 $24 \%$ 이며, $6.89 \mathrm{MPa}$ 인 경우엔 $17 \%, 20.68 \mathrm{MPa}$ 이상인 경우 마찰계수는 $6 \%$ 이다. 이를 본 연구에서 측정된 마찰계수 와 비교해 보면 PTFE 마찰재와 $\mathrm{PVDF} / \mathrm{MgO}$ 마찰재는 비슷 한 수준의 마찰성능을 나타내는 것을 확인할 수 있었다. 그리 고 PTFE 마찰재를 이용하여 동일한 조건으로 실험을 진행한 후 발생하는 마모를 비교한 결과, $\mathrm{PVDF} / \mathrm{MgO}$ 마찰재가 $\mathrm{PTFE}$ 마찰재에 비해 마모가 현저히 적게 발생하였다(Fig. 7). 따라서 $\mathrm{PVDF} / \mathrm{MgO}$ 마찰재는 PTFE 마찰재보다 내마모성이 우수하 며, 마찰면진장치의 마찰재로써의 충분한 수준의 마찰성능을 나타내는 것으로 확인하였다. 마찰계수 측정시험으로 확인한 마찰계수 중, 동마찰계수를 해석모델에 적용하기 위해 속도가 $50 \mathrm{~mm} / \mathrm{sec}$ 일 때와 상부구조의 중량을 고려하여 면압이 $30 \mathrm{MPa}$ 인 경우의 마찰계수를 이용하였다. 또한, Fig. 6의 하중-변위 응답에서 확인할 수 있는 초기강성 $\left(\mathrm{K}_{u}\right.$, Table 2)을 함께 이용

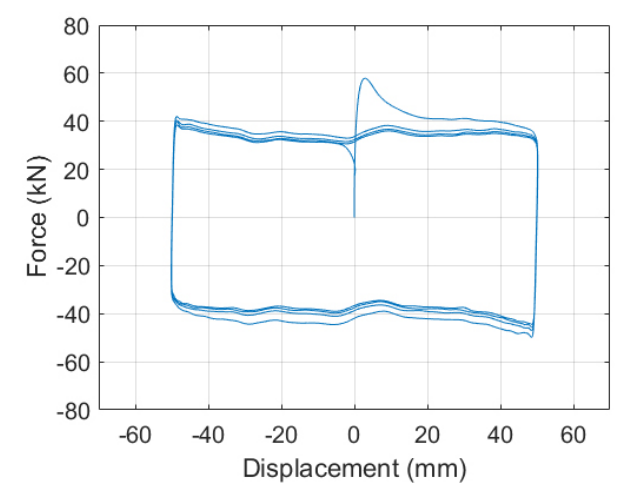

Fig. 6 Force-displacement response of friction material sample(Velocity: $50 \mathrm{~mm} / \mathrm{sec}$, Contact pressure: $30 \mathrm{MPa}$ )

Table 1 Friction coefficient of friction material sample

\begin{tabular}{|c|c|c|}
\hline Velocity $(\mathrm{mm} / \mathrm{sec})$ & Contact pressure(MPa) & Friction coefficient(\%) \\
\hline \multirow{3}{*}{1} & 10 & 9.74 \\
\cline { 2 - 3 } & 20 & 6.74 \\
\cline { 2 - 3 } & 30 & 5.57 \\
\hline \multirow{3}{*}{50} & 10 & 11.91 \\
\cline { 2 - 3 } & 20 & 8.10 \\
\cline { 2 - 3 } & 30 & 6.59 \\
\hline
\end{tabular}



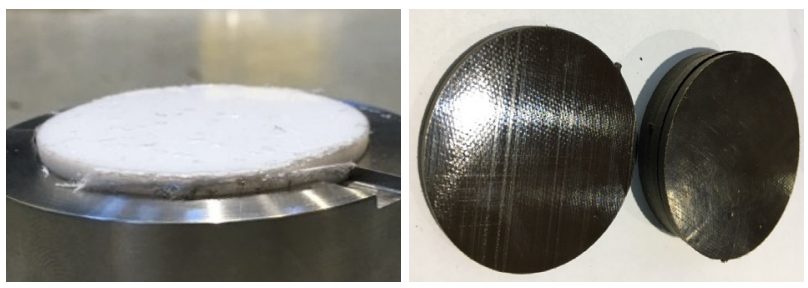

Fig. 7 Condition of friction material specimens after measuring friction coefficient

Table 2 Initial stiffness of friction material sample

\begin{tabular}{|c|c|}
\hline Sample & PVDF/MgO friction material \\
\hline Initial stiffness $\left(\mathrm{K}_{\mathrm{u}}, \mathrm{kN} / \mathrm{m}\right)$ & $17,337.42$ \\
\hline
\end{tabular}

하여 마찰면진장치를 모델링하였다. 기존 연구에서 사용된 교 량모델에 모델링한 마찰면진장치를 적용한 후 지진하중에 대 한 교량의 응답을 확인함으로써 마찰재의 성능을 평가하였다.

\section{4. 마찰면진장치를 적용한 2 경간 교량의 지진해석}

\section{1 마찰면진장치 모델링}

기존 연구(Aviram et al., 2008)에서 사용된 2경간 교량에 마 찰면진장치를 적용하기 위해 마찰면진장치를 추가로 모델링 하였다. 마찰면진장치는 마찰면의 개수에 따라 여러 종류로 나뉘는데, 본 연구에서는 마찰재의 성능을 평가하는 것이 목 적이므로 비교적 간단하게 마찰면이 1 개인 마찰면진장치를 이용하였고, Open System for Earthquake Engineering Simulation (OpenSees, McKenna et al., 2000)에서 정의한 SingleFPBearing 요소를 이용하였다. 마찰면진장치는 마찰재의 마찰력과 마찰면 의 곡률로 인해 지진에너지를 소산하며 마찰재료의 마찰력으로 인한 초기강성과 마찰면의 곡률로 인한 항복 후 강성으로 구분 되어 거동한다. Fig. 8 에 거동 특성을 도식화하여 나타내었다.

Fig. 8에 나타낸 하중-변위 응답에서 $K_{u}$ 가 마찰재의 마찰력 으로 인한 초기강성을 의미하며, $K_{d}$ 는 마찰면의 곡률로 인한 항

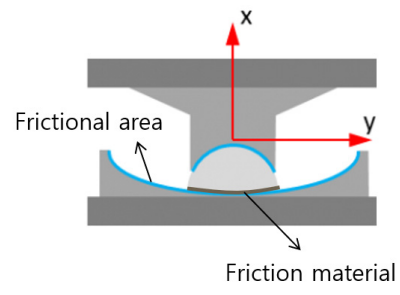
system (a) Single friction pendulum

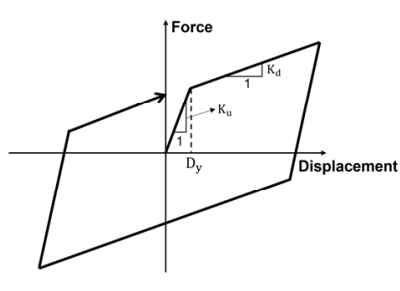

(b) Force-displacement response
Fig. 8 Schematic and force-displacement response for friction pendulum system

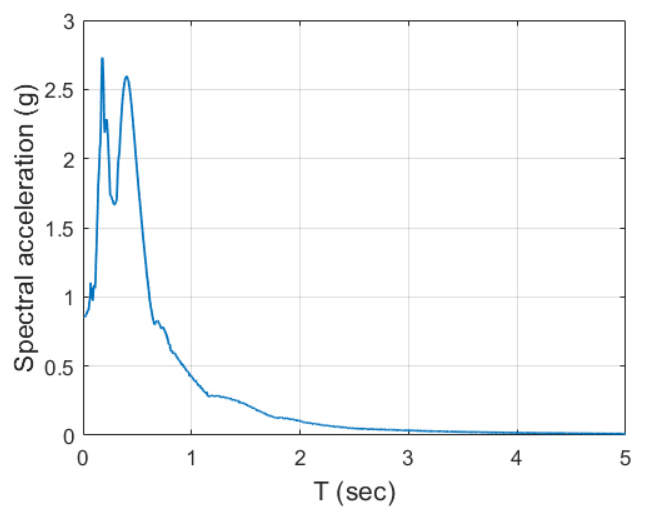

Fig. 9 Acceleration response spectra of input ground motion (Kobe, 1995)

복 후 강성을 의미한다. OpenSees에서 정의한 singleFPBearing 요소에서는 이와 같은 거동을 나타내기 위해 입력변수로 초기 강성과 마찰재의 마찰계수, 곡률을 사용한다. 초기강성은 마찰 계수 측정실험을 위해 얻은 하중-변위 응답(Fig. 6)에서 계산하 였으며, 곡률은 입력 지진파 중 가장 높은 최대지반가속도(peak ground acceleration, PGA)를 가지는 입력 지진파의 응답 가속 도(Fig. 9) 최댓값을 피하도록 목표 주기를 2 초로 선정한 후 다 음 식 (1)을 통해 계산하여 $1 \mathrm{~m}$ 로 설정하였다.

$$
T=2 \pi \sqrt{\frac{R}{g}}
$$

여기서, $T$ 는 목표 주기, $R$ 은 마찰면의 곡률반지름, $g$ 는 중력 가속도이다. 식 (1)을 통해 계산하여 곡률반지름을 지정하면, 다음 식 (2)를 통해 항복 후 강성이 계산되어 singleFPBearing 요소에 적용된다.

$$
K_{d}=\frac{W}{R}
$$

여기서, $W$ 는 구조물의 수직 재하하중이다. 본 논문에서 사용 된 마찰계수와 초기강성은 3.2절의 Tables 1,2 에 각각 나타낸 값을 이용하였다. 이처럼 모델링한 마찰면진장치를 2경간 교 량모델의 교각과 교대에 적용하여 상부구조와 하부구조를 격 리시킨 면진된 교량으로 모델링하였다. 사용된 교량모델에 관 한 설명은 4.2절에 기술하였다.

\section{2 교량 구조해석 모델}

본 논문에서 사용한 교량모델은 Aviram 등(2008)의 연구에 서 사용되었던 2경간 교량인 R14 교량을 이용하였다. R14 교 
량은 교각이 2 개인 철근콘크리트 교량이며, 2 개의 교각이 지 반부터 상부구조까지 연결된 라멘 구조를 이루고 있다(Fig. 10).

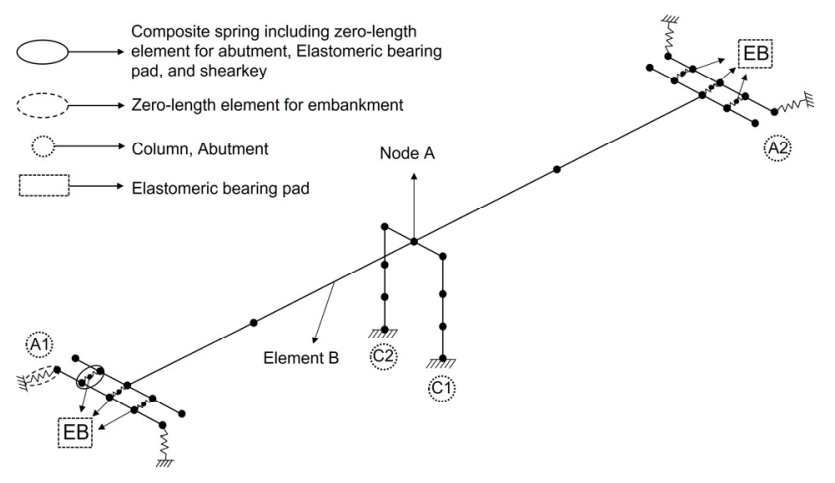

(a) Original bridge

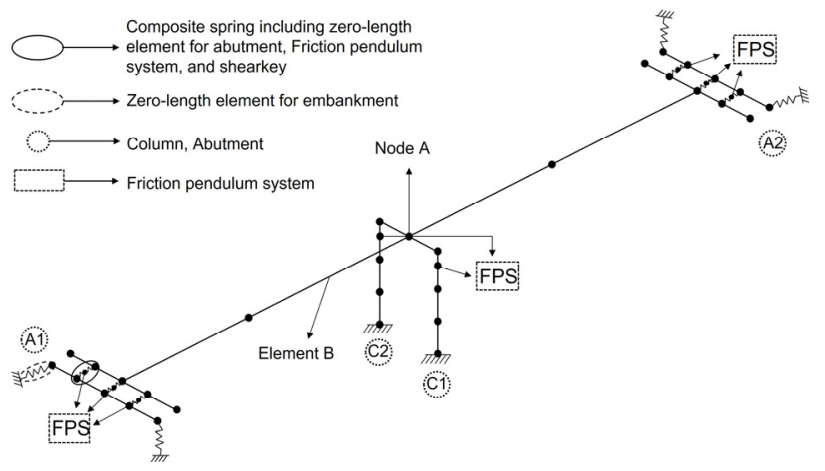

(b) Isolated bridge with friction pendulum system

Fig. 10 Analytical models of R14 bridge

Table 3 Characteristics of R14 bridge(Aviram et al., 2008)

\begin{tabular}{|c|c|}
\hline Parameter & Value and description \\
\hline Total length of the bridge & $87.123 \mathrm{~m}$ \\
\hline Length of each deck span & $44.20 \mathrm{~m}, 42.98 \mathrm{~m}$ \\
\hline Deck width & $16.37 \mathrm{~m}$ \\
\hline Deck depth & $1.72 \mathrm{~m}$ \\
\hline Deck cross-sectional properties & $\begin{array}{l}A=8.27 \mathrm{~m}^{2}, I_{y}=3.868 \mathrm{~m}^{4} \\
I_{z}=163.871 \mathrm{~m}^{4} \\
A_{v y}=2.0 \mathrm{~m}^{2}, A_{v z}=5.029 \mathrm{~m}^{2}\end{array}$ \\
\hline Column Diameter & $1.65 \mathrm{~m}$ \\
\hline Column height & $10.580 \mathrm{~m}$ \\
\hline Deck centroid to column top & $0.98 \mathrm{~m}$ \\
\hline Cap beam length & $3.645 \mathrm{~m}$ \\
\hline Cap beam cross-sectional area & $2.3 \mathrm{~m} \times 1.75 \mathrm{~m}$ \\
\hline Unit weight of reinfirced concrete & $23.564 \mathrm{kN} / \mathrm{m}^{2}$ \\
\hline Reinforcement details of column & $\begin{array}{l}\text { Longitudinal rebar: \#14(42ea) } \\
\text { Transverse rebar: \#7(0.125m spacing) }\end{array}$ \\
\hline Gap between abutment and deck & $0.0508 \mathrm{~m}$ \\
\hline $\begin{array}{l}\text { Foundation type as boundary } \\
\text { condition }\end{array}$ & Fixed condition \\
\hline Expansion joint & Not applicable \\
\hline
\end{tabular}

교량의 상부구조는 교량의 거동에 영향을 끼치는 질량의 대부분 을 차지하고 있으므로 교량의 정확한 응답을 얻기 위해서는 적용 되는 질량이 적절히 배분되어야 한다. 따라서, 상부 구조에서는 교축직각방향의 집중질량 뿐만 아니라 교축방향의 회전질량까 지 고려되어 튜닝 포크 모델(tuning-fork model)로 모델링되었다.

교대의 경우 교량받침 혹은 면진장치, 전단키 등 각 구성 요소 의 거동을 동시에 고려해야 하므로 Mackie와 Stojadinovic(2006) 가 개발한 스프링 교대가 적용되었다. 이를 통해 교량받침, 뒤 채움 흙, 콘크리트의 거동을 적용하여 상부구조의 거동을 통해 발생되는 하중이 교량받침과 교대를 통해 기초로 전달되는 것 과 교대 뒷부분의 뒤채움 흙으로 전달되는 경로로 총 두 가지 경로를 표현할 수 있도록 모델링되었다. 교량의 주된 기하학적 물성 정보는 Table 3 에 나타내었다. 기존 R14 교량에 면진장치 를 추가하여 상부구조와 하부구조를 이격시킨 면진된 R14 교 량으로 모델링하였다. 기존 R14 교량(Fig. 10(a))과 면진된 R14 교량(Fig. 10(b))에 대해 지진해석을 수행하고, 두 교량의 응답 을 비교분석하여 $\mathrm{PVDF} / \mathrm{MgO}$ 마찰재의 성능을 평가하였다.

\section{$4.3 \mathrm{R} 14$ 교량의 비선형 시간이력 해석}

기존의 R14 교량모델과 면진된 R14 교량모델을 이용하여 비선형 시간이력 해석을 수행하고, 교량 응답의 비교분석을 통해 마찰재의 성능을 확인하였다. 1995년 1월 17일에 발생했 던 고베 지진파를 포함한 Aviram 등(2008) 연구에서 사용되었 던 5 개의 지진파를 이용하여 지진해석을 수행하였다. 사용한 지진파 중 높은 $\mathrm{PGA}$ 를 가지는 고베 지진파의 시간 이력 곡선 을 Fig. 11에 나타내었다.

기존의 R14 교량과 마찰재를 적용한 R14 교량의 상부구조 응답을 비교하여 개발한 마찰재를 적용한 마찰면진장치의 성 능을 확인하였다. 상부구조의 응답은 A 절점(Node A, Fig. 10) 의 변위와B 요소(Element B, Fig. 10)에 발생하는 힘을 교축 방 향, 교축 직각 방향, 수직 방향으로 비교하였다. 그 결과, 세 방 향의 응답 모두 마찰면진장치를 적용했을 때 동일한 경향이 나 타났으며, 5 개의 지진파에 대한 응답 모두 동일하였다. 그러므

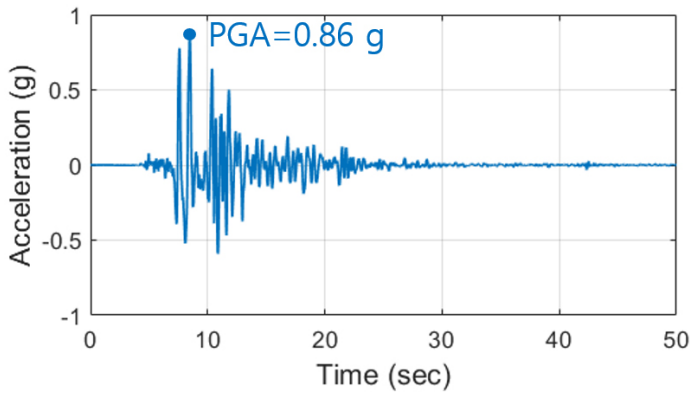

Fig. 11 Input ground motion(Kobe, 1995) 


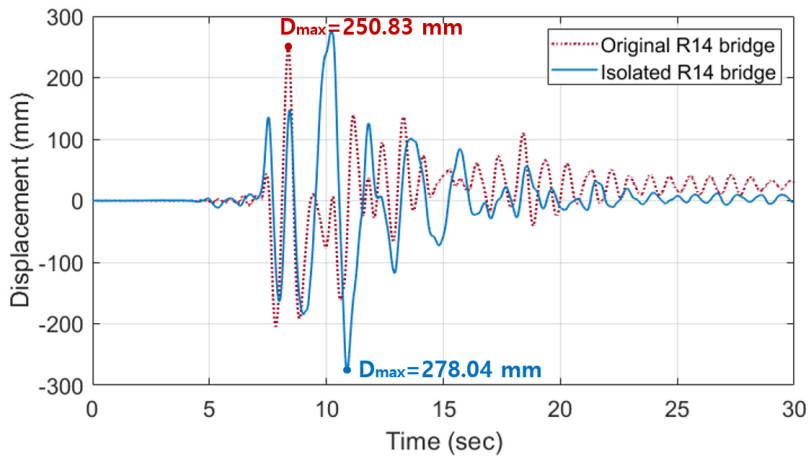

Fig. 12 Displacement of node A from R14 bridges

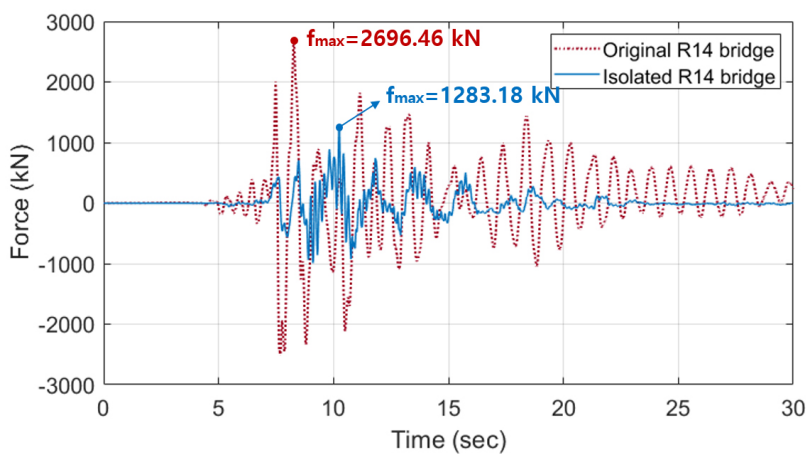

Fig. 13 Force in element B from R14 bridges

로 세 방향 중, 가장 큰 응답이 발생한 교축 직각 방향으로 고베 지진에 대한 응답들을 살펴보았다. Fig. 12는 R14 교량 상부 A 절점의 절대변위를, Fig. 13 은 B요소 A절점에 작용하는 교축 직각방향의 힘을 제시하였다. 다른 지진파에 대한 응답은 Tables 4, 5에 각각의 최댓값을 나타내었다.

$\mathrm{A}$ 절점에서 5 개의 지진파에 대한 응답 모두 면진된 R14 교 량의 상부구조가 마찰면진장치가 적용되지 않은 기존의 R14 교량보다 주기가 증가하는 것을 확인할 수 있었다. 또한, $\mathrm{B}$ 요 소의 응답에서도 마찰면진장치가 적용된 경우 주기가 증가하 는 것을 확인할 수 있었고, 면진된 R14 교량은 기존의 R14 교 량보다 지진으로 인해 구조물에 발생되는 힘이 약 $50 \%$ 이상 감소하는 것을 확인할 수 있었다. 이는 마찰면진장치가 구조 물을 장주기화시키고, 지진이 발생하였을 때 구조물에 작용되 는 하중을 장치가 일부 수용함으로써 구조물에 발생하는 피해 를 줄이는 마찰면진장치의 특성이다. 비선형 시간이력 해석에 서 개발한 $\mathrm{PVDF} / \mathrm{MgO}$ 마찰재를 적용하더라도 마찰면진장치 의 특성이 나타났으며, $\mathrm{PVDF} / \mathrm{MgO}$ 마찰재가 마찰면진장치의 마찰재로 활용될 수 있는 가능성을 확인하였다.

\section{5. 결 론}

본 논문에서는 마찰면진장치의 성능을 향상시키기 위해 새 로운 마찰재를 개발하였다. 재료로는 상용화된 PTFE의 대체
Table 4 Displacemenet of node A from R14 bridges for input ground motions

\begin{tabular}{|c|c|c|}
\hline \multirow{2}{*}{$\begin{array}{c}\text { Input } \\
\text { ground motions }\end{array}$} & \multicolumn{2}{|c|}{ Displacment(mm) } \\
\cline { 2 - 3 } $\begin{array}{c}\text { Ground motion 1 } \\
\text { (PGA: } 0.57 \mathrm{~g} \text { ) }\end{array}$ & 70.13 & 178.20 \\
\hline $\begin{array}{c}\text { Ground motion } 2 \\
\text { (PGA: } 0.49 \mathrm{~g})\end{array}$ & 108.21 & 140.70 \\
\hline $\begin{array}{c}\text { Ground motion 3 } \\
\text { (PGA: } 0.41 \mathrm{~g})\end{array}$ & 19.88 & 64.44 \\
\hline $\begin{array}{c}\text { Ground motion } 4 \\
\text { (PGA: } 0.28 \mathrm{~g})\end{array}$ & 34.83 & 132.05 \\
\hline
\end{tabular}

Table 5 Force in element B from R14 bridges for input ground motions

\begin{tabular}{|c|c|c|}
\hline \multirow{2}{*}{$\begin{array}{c}\text { Input } \\
\text { ground motions }\end{array}$} & \multicolumn{2}{|c|}{ Force(kN) } \\
\cline { 2 - 3 } $\begin{array}{c}\text { Ground motion 1 } \\
\text { (PGA: } 0.57 \mathrm{~g} \text { ) }\end{array}$ & 2061.52 & 754.83 \\
\hline $\begin{array}{c}\text { Ground motion } 2 \\
\text { (PGA: } 0.49 \mathrm{~g} \text { ) }\end{array}$ & 2274.68 & 695.47 \\
\hline $\begin{array}{c}\text { Ground motion 3 } \\
\text { (PGA: } 0.41 \mathrm{~g} \text { ) }\end{array}$ & 685.81 & 364.34 \\
\hline $\begin{array}{c}\text { Ground motion } 4 \\
\text { (PGA: } 0.28 \mathrm{~g} \text { ) }\end{array}$ & 1465.9 & 557.69 \\
\hline
\end{tabular}

재로 평가받는 PVDF와 내마모성을 증가시키기 위해 $\mathrm{MgO}$ 를 함께 이용하여 마찰재를 개발하였다. 기존 연구에서 $\mathrm{MgO}$ 가 $10 \%$ 치환되었을 때 내마모성이 가장 높은 것을 제시하였으므 로 $\mathrm{MgO}$ 가 $10 \%$ 치환된 $\mathrm{PVDF} / \mathrm{MgO}$ 마찰재를 제작하여 마찰 계수를 확인하였다. 마찰계수 측정은 AASHTO 가이드라인에 따라 측정되었으며 AASHTO 가이드라인에 나타나 있는 PTFE 마찰재의 마찰계수와 비교하여 $\mathrm{PVDF} / \mathrm{MgO}$ 마찰재의 마찰성 능을 확인하였다. 그 결과, 개발한 $\mathrm{PVDF} / \mathrm{MgO}$ 마찰재의 마찰 성능은 PTFE 마찰재와 유사한 것을 확인할 수 있었다.

측정된 마찰계수를 이용하여 마찰면진장치를 설계한 뒤 2 경간 교량인 R14 교량모델에 적용하여 면진된 R14 교량모델 로 모델링하였다. 기존의 R14 교량모델과 면진된 R14 교량모 델을 이용하여 비선형 시간이력 해석을 수행하였고 상부구조 에 발생하는 변위와 힘을 비교분석 하여 마찰면진장치의 성능 을 확인하였다. 비교분석 결과, 면진된 R14 교량모델에서 교 량의 주기가 증가하였고, 지진 발생 시 교량에 발생하는 힘이 약 $50 \%$ 이상 감소하는 것을 확인할 수 있었다. 이는 지진 발생 시 마찰면진장치가 상부구조를 장주기화시키며 장치가 변위 와 하중을 일정 구간 수용하여 구조물에 발생하는 피해를 줄이 는 마찰면진장치의 특성이다. 그러므로 비선형 시간이력 해석 을 통해 개발한 $\mathrm{PVDF} / \mathrm{MgO}$ 마찰재를 적용한 마찰면진장치의 성능이 발현되는 것을 확인하였으며 $\mathrm{PVDF} / \mathrm{MgO}$ 마찰재가 마 찰재로써 활용될 수 있을 것으로 판단하였다. 
기존 마찰재(PTFE)에 비하여 내마모성이 개선된 개발 마찰 재는 유사한 마찰성능을 가지고, 면진장치가 적용된 구조물의 내진성능을 기존 마찰재와 같이 향상시킬 수 있는 것으로 확인 하였다. 향후에는 개발한 마찰재를 이용하여 실스케일의 마찰 면진장치를 제작하여 실험을 통해 성능을 평가할 예정이다. 또, 제작된 마찰면진장치를 이용하여 해석모델로 모델링하고 여러 가지 지진파를 이용한 상세해석과 확률론적 분석 방법인 취약도 분석을 통해 $\mathrm{PVDF} / \mathrm{MgO}$ 마찰재의 성능평가에 관한 연 구를 진행할 예정이다.

\section{감사의 글}

본 연구는 산업통상자원부(MOTIE)와 한국에너지기술평가원 (KETEP)의 지원을 받아수행한 연구 과제입니다(20194030202460).

\section{References}

American Association of State Highway and Transportation Officials (AASHTO) (2010) Guide Specifications for Seismic Isolation Design, American Association of State Highway and Transportation Officials.

Aviram, A., Mackie, K.R., Stojadinovic, B. (2008) Guidelines for Non-Linear Analysis of Bridge Structures in California, Rep. No. 2008/03, Pacific Earthquake Engineering Research Center, Univ. of California, Berkely.

Burris, D.L., Sawyer, W.G. (2006) Improved Wear Resistance in Alumina-PTFE Nanocomposites with Irregular Shaped Nanoparticles, Wear, 260, pp.915 918.

Castaldo, P., Palazzo, B., Della Vecchia, P. (2015) Seismic Reliability of Base-Isolated Structures with Friction Pendulum Bearings, Eng. Struct., 95, pp.80 93.
Jangid, R.S. (2005) Optimum Friction Pendulum System for Near-Fault Motions, Eng. Struct., 27, pp.349 359.

Kim, S.J., Kim, S.Y., Ji, Y.S., Kim, B.S., Han, T.S. (2020) Study on the Performance Verification of PRB Isolation Device using Simulation and Experiment, J. Comput. Struct. Eng. Inst. Korea, 33, pp.311 318.

Liu, B., Chen, C., Li, T., Crittenden, J., Chen, Y. (2013) High Performance Ultrafiltration Membrane Composed of PVDF Blended with its Derivative Copolymer PVDF-g-PERMA, J. Membr. Sci., 445, pp.66 75.

Lu, L.Y., Lee, T.Y., Yeh, S.W. (2011) Theory and Experimental Study for Sliding Isolators with Variable Curvature, Earthq. Eng. \& Struct. Dyn., 40, pp.1609 1627.

Mackie, K.R., Stojadinovic, B. (2006) Post-Earthquake Functionality of Highway Overpass Bridges, Earthq. Eng. \& Struct. Dyn., 35, pp.77 93.

McKenna, F., Fenves, G., Jeremic, B., Scott, M. (2000) Open System for Earthquake Engineering Simulation (OpenSees), University of California, Berkeley.

Medhekar, M.S., Kennedy, D.J.L. (2000) Displacement-based Seismic Design of Buildings, Eng. Struct., 22, pp.201 209.

Park, M.S., Sung, H.S., Park, C.H., Han, T.S., Kim, J.H. (2019) High Triboligy Performance of Poly (Vinylidene Fluoride) Composites based on Three-Dimensional Mesoporous Magnesium Oxide Nanosheets, Compos. Part B: Eng., 163, pp.224 235.

Takeichi, Y., Bibowo, A., Kawamura, M., Uemura, M. (2008) Effect of Morphology of Carbon Black Fillers on the Tribological Properties of Fibrillated PTFE, Wear, 264, pp.308 315.

\section{요 지}

구조물을 지진 위험으로부터 완화시키기 위한 마찰면진장치의 상용화된 마찰재료 중 폴리테트라플루오로에틸렌(polytetrafluoroethylene, PTFE)은 내화학성과 마찰성능이 우수하다. 그러나 PTFE는 상대적으로 낮은 내마모성을 가지므로 경제적인 마찰재료이며 산화마그 네슘(oxide magnesium, $\mathrm{MgO}$ )으로 내마모성을 증가시킨 개선된 폴리비닐리덴 플루오라이드(polyvinylidene fluoride, PVDF)를 PTFE 의 대안으로 제안하였다. 개발된 PVDF/MgO 마찰재를 이용하여 실험을 통해 마찰성능을 측정하였으며 PTFE의 마찰성능과 비교하 였다. 그리고 측정된 마찰계수를 이용하여 마찰면진장치를 설계하였다. 마찰면진장치의 성능은 교량의 비선형 시간이력 해석을 통해 확인하였고, 이를 통해 마찰면진장치의 마찰재료로 PTFE를 대체하여 PVDF/MgO를 사용하는 것에 대한 타당성을 평가하였다.

핵심용어 : 지진격리장치, 마찰면진장치, 비선형 시간이력 해석, OpenSees 